\title{
A substitution in the pre-S1 promoter region is associated with the viral regulation of hepatitis $B$ virus
}

Suguru Ogura ${ }^{1 \dagger}$, Masahiko Tameda $^{1 \dagger}$, Kazushi Sugimoto $^{1,2^{*}}$, Makoto Ikejiri $^{2}$, Masanobu Usui ${ }^{3}$, Masaaki Ito $^{4}$ and Yoshiyuki Takei ${ }^{1}$

\begin{abstract}
Background: Much evidence has demonstrated the influence of Hepatitis B virus (HBV) mutations on the clinical course of HBV infection. As large $(L)$ protein plays a crucial role for viral entry, we hypothesized that mutations in the pre-S1 promoter region might affect the expression of $\mathrm{L}$ protein and subsequently change the biological characters of virus.

Methods: Patients infected with genotype C HBV were enrolled for analysis. HBV DNA sequences were inserted into a TA cloning vector and analyzed. To evaluate the effects of mutations in the pre-S1 promoter region, promoter activity and the expression of mRNA and L protein were analyzed using HepG2 cells.

Results: In total, 35 patients were enrolled and 13 patients (37.1\%) had a single base substitution in the pre-S1 promoter region; the most frequent substitution was a G-to-A substitution at the 2765th base (G2765A) in the Sp1 region. The HBV viral load showed a negative correlation with the substitution ratio of the Sp1 region or G2765A ( $r=-0.493$ and -0.473 , respectively). Among those with a viral load $\leq 5.0 \mathrm{log} \mathrm{IU} / \mathrm{ml}$, patients with the G2765A substitution showed a significantly lower HBV viral load than those with the wild-type sequence. HepG2 cells transfected with the G2765A substitution vector showed reduced luciferase activity of the pre-S1 promoter, as well as reduced expression of pre-S1 mRNA and L protein. Furthermore, the G2765A substitution greatly reduced the $L$ protein expression level of vector-produced virus particles.
\end{abstract}

Conclusion: G2765A substitution in the pre-S1 promoter reduced the expression of $L$ protein and resulted in a low viral load and less severe disease in chronic HBV infections.

Keywords: Hepatitis B virus, Mutation, Pre-S1 promoter, L protein

\section{Background}

Despite the promotion of vaccination, HBV infection remains one of the leading causes of severe liver disease, such as liver cirrhosis and HCC. According to the World Health Organization, an estimated 257 million people worldwide are currently infected chronically with HBV, and a higher prevalence is found among populations in African and western pacific regions [1]. As of 2011, 1.2 million people in Japan are estimated to be infected with

\footnotetext{
* Correspondence: kazushi@clin.medic.mie-u.ac.jp

† Suguru Ogura and Masahiko Tameda contributed equally to this work.

1Department of Gastroenterology and Hepatology, Mie University Graduate

School of Medicine, 2-174 Edobashi, Tsu, Mie 514-8507, Japan

${ }^{2}$ Department of Central Laboratory, Mie University Hospital, Tsu, Japan

Full list of author information is available at the end of the article
}

HBV [2], and genotype $\mathrm{C}$ has been reported to be the most dominant strain in Japan, accounting for more than $80 \%$ of the chronic infections [3].

HBV is a hepatotropic DNA virus that belongs to the Hepadnaviridae family. It contains a partially doublestranded relaxed circular DNA of approximately 3200 nucleotides from which four mRNAs are transcribed, i.e., 0.7-, 2.1-, 2.4-, and 3.5-kb mRNAs. The envelope proteins of HBV consist of, in descending order of size, L protein, M protein, and $\mathrm{S}$ protein. L protein is translated from the 2.4-kb mRNA, and the $\mathrm{M}$ and $\mathrm{S}$ proteins are translated from the $2.1-\mathrm{kb}$ mRNA. A polymerase, i.e., a reverse transcriptase lacking proofreading activity, is translated from the $3.5-\mathrm{kb}$ mRNA. The error-prone feature of this polymerase causes a

(C) The Author(s). 2019 Open Access This article is distributed under the terms of the Creative Commons Attribution 4.0 International License (http://creativecommons.org/licenses/by/4.0/), which permits unrestricted use, distribution, and 
high mutation rate that is estimated to be $10^{-3}$ to $10^{-6}$ substitutions per replication cycle, which is more than 10-fold higher that of other DNA viruses [4-6]. HBV mutations may be selected for by immune responses or antiviral therapies, and the species with advantages in replication, assembly, secretion, or infectivity become dominant.

Much evidence has demonstrated the influence of HBV mutations on the clinical course of HBV infection. One of the most common mutations of HBV is G1896A at the precore region that converts TGG to TAG, a stop codon, which abolishes the expression of hepatitis $\mathrm{B}$ e antigen (HBeAg). Double mutations, A1762T and G1764A, in the basic core promoter region result in decreased HBeAg expression and enhanced viral genome replication; these mutations are frequently found in HBeAg-negative chronic hepatitis patients [7]. These mutations were documented as predictors of HCC risk [8]. Nucleos(t)ide analogues (NAs) are currently used for the treatment of HBV as they can inhibit the reverse transcription of HBV. However, long-term usage of NAs may lead to the development of drug resistance due to selective pressure [9]. In the surface protein region, mutations in the " $\alpha$ " determinant, which is the major target of the neutralizing B cell response, are known to be associated with immune escape [10]. In addition, PreS1 and/or preS2 deletions and preS2 start codon mutations reduce hepatitis B surface antigen (HBsAg) titer [11].

Recently, sodium taurocholate co-transporting polypeptide (NTCP) has been identified as a host receptor of HBV. NTCP is a bile salt transporter that is expressed on the surface of hepatocytes; it binds to the N-terminus of the L protein, which triggers viral entry [12]. In addition to this, $\mathrm{L}$ protein has several other biological functions. It is necessary for virion maturation by binding to core particles [13]. Also, the pre-S1 domain contains many $\mathrm{T}$ - and B-cell epitopes that play essential roles in the interaction with the immune system [14]. Furthermore, an inappropriate $\mathrm{L} / \mathrm{S}$ ratio leads to the inhibition of virion secretion [15], and L protein is also involved in the regulation of covalently closed circular DNA (cccDNA) [16]. As described above, L protein is translated from the 2.4-kb mRNA, different from the 2.1-kb mRNA coding the $\mathrm{S}$ and $\mathrm{M}$ proteins, and its transcription is regulated by the HNF1, HNF3, Sp1, and TATA transcription factors via binding to recognition sequence that are located upstream of the pre-S1 domain [17-19]. These promoters contain specific nucleotide sequences that transcription factors can bind to and increase transcription activity.

Due to the various functions of $\mathrm{L}$ protein, we hypothesized that mutations in the pre-S1 promoter region might affect the expression of $\mathrm{L}$ protein and subsequently change the biological characters of virus and prognosis of HBV infection. To examine this hypothesis, in this study, we investigated the effects of mutations in the pre-S1 promoter region of HBV on biological characters of virus and prognosis using clinical samples and a cultured cell line.

\section{Methods \\ Patients}

Subjects with chronic HBV infection whose HBV DNA was measured at Mie University Hospital between June 2013 and June 2014 were enrolled in this study. Regular blood chemistry tests were performed at the central laboratory of Mie University Hospital. HBV viral loads were also measured at this laboratory by quantitative real-time PCR (qPCR; COBAS TaqMan HBV test v2.0, Roche, Basel, Switzerland). The HBV genotypes were determined by a clinical laboratory testing company (SRL, Tokyo, Japan) and/or by nucleotide sequencing of the pre-S2 region [20]. Aliquots of patient sera were kept at $-30{ }^{\circ} \mathrm{C}$ until the HBV DNA sequence analyses.

Only the patients infected with genotype C HBV were enrolled in the study as it is the most dominant genotype in Japan. The other exclusion criteria included: current or past usage of anti-HBV agents, including interferon and NAs; co-infection with hepatitis $C$ virus or human immunodeficiency virus; association with any other liver disease (autoimmune liver disease, etc.); history of chemotherapy or radiation therapy; and current or past usage of any drugs that could affect the patient's immune status (steroids, immunosuppressants, etc.). We also excluded patients who were diagnosed as having genotype C HBV by the antigenicity of pre-S2 region in the HBsAg (performed by SRL) if the sequence analyses showed conflicting results. In addition, patients with a low HBV viral load $(<1.3 \log \mathrm{IU} / \mathrm{ml})$ were also excluded. This study was approved by the Institutional Review Board of Mie University Hospital. Written informed consent was obtained from each patient included in the study. The study protocol conformed to the ethical guidelines of the 1975 Declaration of Helsinki, as reflected in the a priori approval by the institution's human research committee.

\section{Sequencing of HBV}

HBV DNA was extracted from the serum of each patient using NucleoSpin Virus (Takara Bio, Shiga, Japan) according to the manufacturer's instructions. The PCR products covering the region $211 \mathrm{bp}$ upstream from the start codon of the pre-S1 region to $95 \mathrm{bp}$ downstream from the start codon of the $\mathrm{S}$ region by the primers $\mathrm{S} 1$ and S2 (Table 1) were inserted into a pTAC-1 DynaExpress TA PCR cloning vector (BioDynamics Laboratory, Tokyo, Japan). Competent cells (DH-5 $\alpha$, Toyobo, Osaka, Japan) were transformed with the TA cloning vector and spread on agar. After overnight incubation at $37^{\circ} \mathrm{C}$, at 
Table 1 Primers used for PCR

\begin{tabular}{|c|c|c|}
\hline Name & Sequence (5' to $\left.3^{\prime}\right)$ & Annotation \\
\hline S1 & ATGCCTGCTAGGTTCTATCC & HBV 2637-2656 (sense) \\
\hline S2 & AGACTCTGTGGTATTGTGAGG & HBV 229-249 (antisense) \\
\hline W1 & TTCACCTCTGCCTAATCATCTCATG & HBV 1824-1848 (sense) \\
\hline W2 & AAGTTGCATGGTGCTGGTGAAC & HBV 1801-1822 (antisense) \\
\hline F1 & CGACTCAGGAAACTGCCTGTAAATAGAC & HBV 950-970, pTac1 404-410 (sense) \\
\hline F2 & AGAGCTTGGTGGAATGTTGTG & HBV 4-24 (antisense) \\
\hline F3 & ATTCCACCAAGCTCTGCTAG & HBV 10-29 (sense) \\
\hline F4 & CCAAGCTAGAAGGAAAGAAGTCAGAAGG & HBV 1958-1978, pTac1 498-504 (antisense) \\
\hline F5 & CAGTTCCTGAGTCGTATTACGCGCTGG & pTac1 391-410, HBV 950-957 (antisense) \\
\hline F6 & TTCCTTCTAGCTTGGCGTAATCATGGTC & pTac1 498-517, HBV 1971-1978 (sense) \\
\hline L1 & AGActcgagCTTGGACAAAGGCATTAAAC & Xhol, HBV 2678-2697 (sense) \\
\hline L2 & AGGagatctGAGGCGCTGCGTGTAGTTC & BgIIII, HBV 2787-2806 (antisense) \\
\hline S3 & TGAGTCGTATTACGCGCTGG & pTac1 391-410 (antisense) \\
\hline m5 & AAAGCTGGCATTCTATATAAAAGAG & HBV 2763-2787, Sp1 G2765A (sense) \\
\hline m9 & GCGACATAAGTTCTATATAAAAGAG & HBV 2763-2787, Sp1 whole nucleotide mutation (sense) \\
\hline$m R$ & CCACAGAGTATGTAAATAATGCC & HBV 2740-2762 (antisense) \\
\hline
\end{tabular}

Nucleotides that were substituted with wild type are indicated in bold. Abbreviations: $P C R$ polymerase chain reaction, $H B V$ hepatitis $B$ virus

least 15 clones were picked up and cultured in Luria-Bertani medium. The plasmids were isolated using a QIAprep Spin Miniprep kit (Qiagen, Venlo, Netherlands). The HBV DNA sequences inserted into the TA vectors were analyzed using an ABI3100 DNA sequencer (Applied Biosystems, Waltham, MA). The consensus sequence was defined by searching the GenBank database using the terms: HBV, genotype C, complete genome, Japan.

\section{Next-generation sequencing (NGS)}

The samples were prepared according to the Ion Amplicon Library Preparation (Fusion Method) protocol of Thermo Fisher Scientific (Waltham, MA). Two pairs of primers were designed. One primer pair had the A adapter sequence (5' - CCATCTCATCCCTGCGTGTCTCCGAC TCAG - $3^{\prime}$ ) with a barcode sequence (13 bp for each sample) followed by the proximal end of the target sequence, and the other pair had the trP1 adapter region $\left(5^{\prime}\right.$ - CCTC TCTATGGGCAGTCGGTGAT -3') followed by the distal end of the target sequence. The other fusion primer pair had the adapter sequences $\mathrm{A}$ and trP1 swapped. The sense primer sequence for the target sequence was $5^{\prime}$ - ATGC CTGCTAGGTTCTATCC -3', and the anti-sense primer sequence was $5^{\prime}$ - ATCTGGATTGTTTGAGTTGG -3'. Ten samples with high HBV viral load (8.2-7.2 log IU/ml) were selected and amplified using each primer pair. The PCR products were purified by Agencourt AMPure XP (Beckman Coulter, Brea, CA) and quantitated using the Agilent DNA 1000 kit (Agilent Technologies, Santa Clara, CA). The PCR products were prepared into an equimolar pool of amplicon libraries at the concentration of $100 \mathrm{pM}$.
The amplicon pool was sequenced on an Ion Personal Genome Machine with the Ion 318 Chip (Thermo Fisher Scientific). FASTQ files were output using Ion Torrent Suite Software (Thermo Fisher Scientific). The sequences were trimmed and filtered using Trimmomatic [21], and aligned to the reference sequence using BWA-MEM [22]. The mutations in the $\mathrm{Sp} 1$ region were detected using Integrative Genomics Viewer [23].

\section{Vector constructs}

The whole HBV DNA genomes isolated from patient sera were amplified by PCR using primers W1 and W2 (Table 1). The amplicons were inserted into the pCR4 Blunt TOPO vector (Thermo Fisher Scientific) and sequenced. One clone that had no mutation in the pre-S1 promoter region was selected as a template. A plasmid containing the SapI restriction enzyme recognition sequence was constructed according to a previously reported method [24]. After the plasmid was digested by SapI, it was self-ligated with T4 DNA ligase to make a full-length circular HBV structure. Using this structure as a template, a plasmid containing a 1.3-fold HBV genome was constructed according to a previously described method [25] with modifications as follows. Circular HBV DNA was amplified by PCR using the primer pairs $\mathrm{F} 1$ and F2, and F3 and F4, and the pTac1 TA cloning vector was amplified using primers F5 and F6 (Table 1). The three amplicons were ligated using the In-Fusion HD Cloning Kit (Takara Bio) to create a 1.3-fold HBV genome vector construct, which was transformed into competent cells (pTac-1 1.3-fold HBV genome). 
Luciferase vectors were constructed using the following methods. PCR products that covered the region 170 bp upstream from the start codon of the pre-S1 region to $41 \mathrm{bp}$ upstream from the start codon of the pre-S1 region were amplified with primers L1 and L2 (Table 1), which also added a sequence recognized by the XhoI or BglII restriction enzyme, respectively. The amplicon and pNL1.1 [Nluc] vector (Promega, Madison, WI) were digested by XhoI and BglII, then ligated and transformed into competent cells (pNL1.1[Nluc] pre-S1 promoter). The $\mathrm{L}$ protein expression vector was constructed by an inverse PCR method [26]. The 1.3-fold HBV genome vector was amplified with primers S1 and S3 (Table 1). The amplicon covered the region $211 \mathrm{bp}$ upstream from the start codon of the pre-S1 region to the poly-A signal region was circularized using $\mathrm{T} 4$ ligase, then transformed into competent cells (pTac-1 pre-S1 expression).

The mutation vectors were constructed by the inverse PCR method using primer m5 (G2765A), a sense primer for the G-to-A substitution at the third nucleotide of the $\mathrm{Sp} 1$ region, and primer $\mathrm{m} 9$ (whole nucleotide mutation), a sense primer for a whole nucleotide mutation of the Sp1 region, and antisense primer $\mathrm{mR}$ (Table 1). The pNL1.1[Nluc] pre-S1 promoter, pTac-1 pre-S1 expression, and pTac-1 1.3-fold HBV genome vectors were amplified using these primers pairs, and the amplicons were circularized using T4 ligase, then transformed into competent cells. The structures of the vectors are detailed in Fig. 1a.

\section{Cell culture and vector transfection}

The human HCC cell line HepG2 (RCB1648) was purchased from the RIKEN BRC Cell Bank (Tsukuba, Japan).
The cells were cultured in Dulbecco's modified Eagle's medium (Life Technologies, Carlsbad, CA) supplemented with $1 \%$ penicillin/streptomycin (Life Technologies) and $10 \%$ fetal calf serum (Life Technologies) in a humidified atmosphere containing $5 \% \mathrm{CO} 2$ at $37^{\circ} \mathrm{C}$.

HepG2 cells were seeded in a 6 -well plate $\left(1 \times 10^{6}\right.$ cells/well) and incubated for $24 \mathrm{~h}$ before transfection. The cells were transfected with $2.5 \mu \mathrm{g}$ of pre-S1 expression vector or the 1.3-fold HBV genome vector using Lipofectamine 3000 reagent (Thermo Fisher Scientific). Protein samples and mRNA samples were collected $48 \mathrm{~h}$ and $24 \mathrm{~h}$ after transfection, respectively.

\section{Luciferase assay}

HepG2 cells were seeded in a 96-well plate $\left(3 \times 10^{4}\right.$ cells/well) and incubated for $24 \mathrm{~h}$ before transfection. The cells were transfected with $50 \mathrm{ng}$ of $\mathrm{Sp} 1$ promoter-inserted pNL1.1 vectors and $50 \mathrm{ng}$ of a pGL4.54 TK promoter control firefly luciferase vector. The cells were analyzed $24 \mathrm{~h}$ after transfection using the Nano-Glo Dual-Luciferase Reporter Assay System (Promega) according to the manufacturer's instructions. The levels of NanoLuc luciferase activity were determined by normalization to the levels of firefly luciferase activity.

\section{RNA extraction and qPCR}

Total RNA was extracted from cultured cells with the RNeasy Mini Kit and RNase-Free DNase Set (Qiagen, Hilden, Germany), and polyA ${ }^{+}$mRNA was purified using Oligote $^{\mathrm{mm}}-\mathrm{dT} 30<$ Super $>$ mRNA Purification Kit (Takara Bio). cDNA was synthesized from $10 \mathrm{ng}$ of mRNA by the extension of oligo dT and random 6 mer primers with

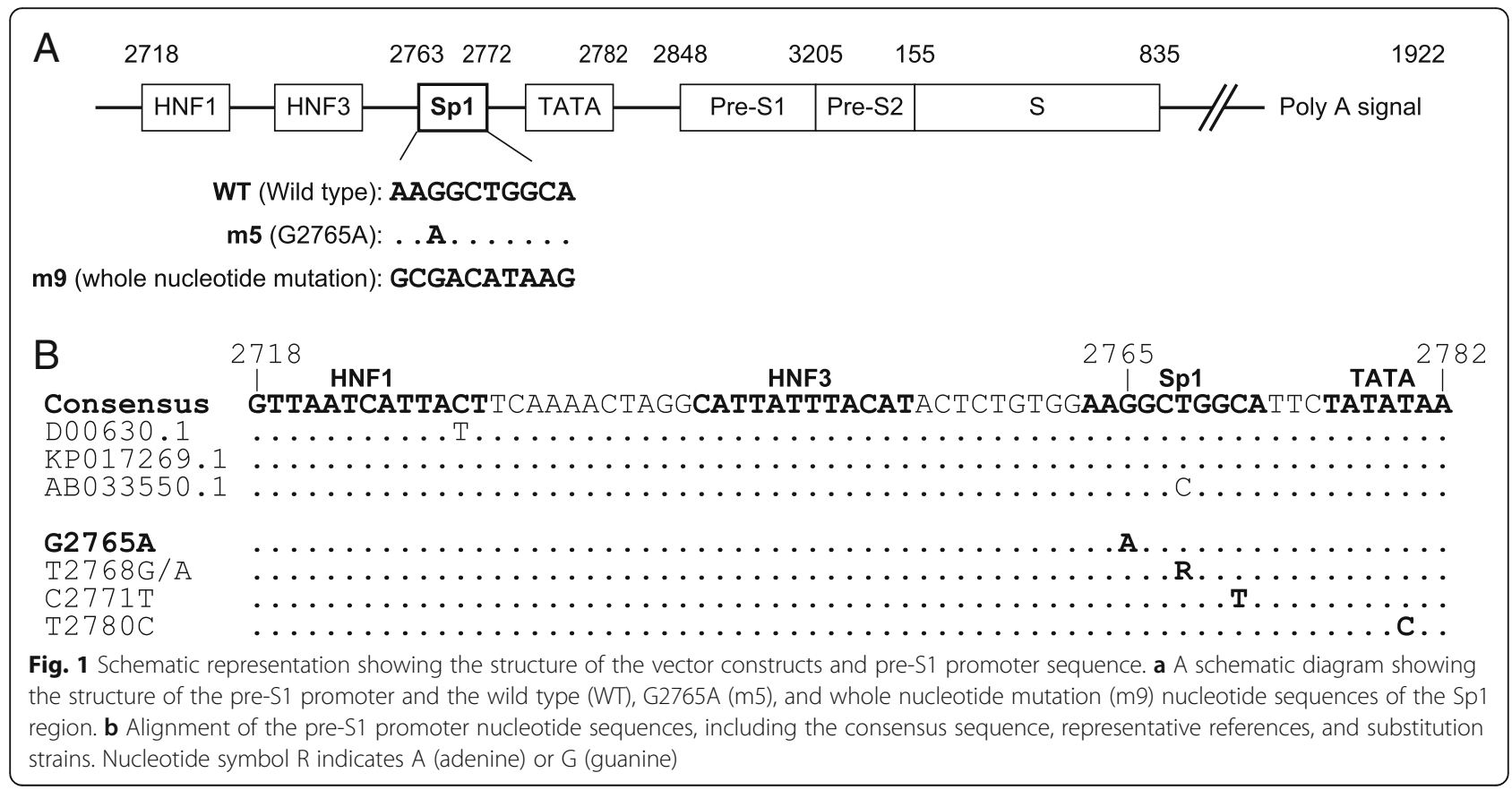


the PrimeScript RT reagent kit (Takara Bio). Subsequently, qPCR was performed using the ABI Prism 7300 Real-Time PCR System (Applied Biosystems, Foster City, CA) with EagleTaq Master Mix kits (Roche Molecular Systems, Branchburg, NJ). The primer and probe sets used for the amplification of the pre-S1 2.4-kb mRNA were 5'aggctcagggcatattgaca $-3^{\prime}, 5^{\prime}$ - gtcttcctgactgccgattg $-3^{\prime}$, and Universal ProbeLibrary Probe \#16 (Roche). The expression levels of the target gene were determined by normalization to $\beta$-actin by the following primers: $5^{\prime}$ aagtccettgccatcctaaaa $-3^{\prime}, 5^{\prime}$ - atgctatcacctcccctgtg $-3^{\prime}$.

\section{Western blot analysis}

Proteins of the cell lysates and cell culture supernatants were separated by sodium dodecyl sulfate polyacrylamide gel electrophoresis and transferred onto polyvinylidene difluoride membranes. The blots were blocked with $5 \%$ milk in Tris-buffered saline with $0.1 \%$ Tween-20 for $1 \mathrm{~h}$, then probed with rabbit polyclonal anti- $\beta$-actin antibody (diluted 1:4000; Abcam, Cambridge, UK), mouse monoclonal anti-HBs antibody (diluted 1:2000; Cosmo Bio, Tokyo, Japan) or mouse monoclonal anti-HBV pre-S1 antibody (diluted 1:4000; Beacle, Kyoto, Japan) at $4{ }^{\circ} \mathrm{C}$ overnight. The immunoblots were then probed with horseradish peroxidase-conjugated anti-mouse secondary antibody (diluted 1:4000; GE Healthcare, Amersham, UK) and visualized using Amersham ECL Prime Western Blotting Detection Reagent (GE Healthcare). Protein amounts were determined by densitometry.

\section{Statistical analysis}

Comparisons of the luciferase activity, mRNA expression, and protein production were performed using the unpaired t-test for comparisons between two groups, one-way ANOVA for comparisons between three groups, or Fisher's exact test for comparisons of categorical variables. Comparison of the clinical parameters was performed using the Mann-Whitney test. The interdependence between two parameters was examined using Spearman's correlation coefficient. $P<0.05$ was considered to be statistically significant.

\section{Results}

\section{Definition of the consensus sequence and vector construction}

Based on the search of the GenBank database, the consensus sequence of the pre-S1 promoter region was defined as shown in Fig. 1b. The full genomic sequence of the HBV DNA strain obtained from a patient that had no mutation in the pre-S1 promoter region and that mostly matched with the consensus sequence was determined and deposited into the DNA Data Bank of Japan under accession number LC360507. This strain was used as a template to construct the vectors.

\section{Identification of the mutations in the pre-S1 promoter region}

In total, 35 patients were enrolled in this study. To assess the mutation in each pre-S1 promoter region, we picked up at least 15 clones from each patient and compared them to the consensus sequence using DNASIS Pro Ver. 2.9 software (Hitachi, Tokyo, Japan); we defined cases in which more than $50 \%$ of the clones had a mutation as cases with a mutation. According to these analyses, 13 patients (37.1\%) had single base substitutions that were detected in the Sp1 and TATA regions of the pre-S1 promoter; the characteristics of these patients are shown in Table 2. Substitutions in the $\mathrm{Sp} 1$ region were found at the 2765th base ( $G$ to A; G2765A), 2768th base ( $\mathrm{T}$ to $\mathrm{G}$ or $\mathrm{A}$ ), and 2771st base ( $\mathrm{C}$ to $\mathrm{T}$ ). A substitution in the TATA region was found at the 2780th base ( $\mathrm{T}$ to C; Fig. 1a). These four substitutions were silent mutations for the polymerase of $\mathrm{HBV}$.

\section{Comparison of viral sequence data acquired by cloning and NGS}

To confirm the integrity of the viral sequence data obtained from cloning, we picked up 10 samples and performed NGS analyses to compare the data derived from both methods. As shown in Table 3, the ratios of the Sp1 G2765A substitution for each sample were mostly comparable between the cloning and NGS data, which verified that our cloning sequence data were reliable.

\section{Relationships between mutations in the pre-S1 promoter region and clinical parameters}

We analyzed whether the mutations in the pre-S1 promoter region affected the clinical parameters. When compared to the patients who had no mutation, the HBV viral load was significantly lower $(p<0.01)$ in those with a mutation; the level of HBsAg was also lower in those with a mutation, but not to the point of statistical significance (Table 2). The Sp1 substitution ratio and the HBV viral load showed a negative correlation $(r=-$ 0.493, $p<0.01$ ), and the Sp1 substitution ratio and the HBsAg level showed a weak negative correlation $(r=-$ $0.348, p<0.05$; Fig. $2 \mathrm{a}$ and b). It is conceivable that a Sp1 substitution is associated with the HBV viral load, so we divided patients into two groups according to the HBV viral load: a high group whose viral load was $>5.0$ $\log \mathrm{IU} / \mathrm{ml}$ and a low group whose viral load was $\leq 5.0 \mathrm{log}$ $\mathrm{IU} / \mathrm{ml} ; 11$ patients were classified into the high group and 24 patients were classified into the low group. Twelve patients in the low group and one patient in the high group had a Sp1 substitution, and the Sp1 substitution ratio was significantly higher in the low group than in the high group (Table $4, p<0.05$ ). The substitution in the TATA region was detected in one patient in the low group. The most frequent substitution was the G2765A 
Table 2 Characteristics of patients with pre-S1 promoter mutant or wild-type HBV

\begin{tabular}{|c|c|c|c|c|}
\hline & All $(n=35)$ & Wild type $(n=22)$ & Mutation $(n=13)$ & $p$ \\
\hline Male $(n(\%))$ & $20(57.1 \%)$ & $10(45.5 \%)$ & $10(76.9 \%)$ & 0.089 \\
\hline Age (years) & $51.7(15-81)$ & $49.2(15-81)$ & $55.9(29-74)$ & 0.432 \\
\hline HBV DNA (log IU/ml) & $5.11(1.3-8.2)$ & $5.22(1.3-8.2)$ & $2.86(1.3-8.2)$ & 0.003 \\
\hline HBsAg (IU/ml) & $13,499(8.61-151,233)$ & $17,788(8.61-151,233)$ & $5634(37.7-19,986)$ & 0.094 \\
\hline HBeAg positive (n (\%)) & $11(31.4 \%)$ & $10(45.5 \%)$ & $1(7.7 \%)$ & 0.027 \\
\hline HBeAb positive (n (\%)) & $24(68.6 \%)$ & $12(54.5 \%)$ & $12(92.3 \%)$ & 0.027 \\
\hline AST $(U / L)$ & $34.5(11-204)$ & $41.4(16-204)$ & $22.7(11-40)$ & 0.035 \\
\hline $\operatorname{ALT}(U / L)$ & $43.8(10-425)$ & $56.5(14-425)$ & $22.4(10-49)$ & 0.127 \\
\hline Platelet count $\left(10^{4} / \mu \mathrm{l}\right)$ & $18.5(10.9-24.2)$ & $18.8(13.9-23.9)$ & $18.0(10.9-24.2)$ & 0.705 \\
\hline
\end{tabular}

Abbreviations: $H B V$ hepatitis B virus, $H B s A g$ hepatitis B surface antigen, $H B e A g$ hepatitis B e antigen, $H B e A b$ hepatitis B e antibody, AST aspartate transaminase, $A L T$ alanine transaminase

substitution, which was found in one patient in the high group and eight patients in the low group. In the low group, the HBV viral load was lower in the patients who had a Sp1 substitution than in those who had no mutation, but the difference was not statistically significant (Table 5). On the other hand, patients who had the G2765A substitution showed a significantly lower HBV viral load and aspartate transaminase (AST) level when compared to those with the wild-type (WT) sequence ( $p$ $<0.05)$. In addition, the G2765A substitution ratio and the HBV viral load showed a negative correlation $(r=-$ $0.473, p<0.01$ ), and the G2765A substitution ratio and the HBsAg level showed a weak negative correlation ( $r=$ $-0.356, p<0.05$; Fig. $2 c$ and d). Therefore, we focused on the G2765A substitution and analyzed its biological function.

\section{A substitution in the $\mathrm{Sp} 1$ site reduced the transcription of pre-S1}

We hypothesized that a substitution in the Sp1 site upstream of the pre-S1 region could affect the transcription of the mRNA coding large HBsAg. To confirm this hypothesis, we first performed a luciferase assay using HepG2 cells. Both m5 (G2765A) and m9 (whole nucleotide mutation) vectors showed significantly impaired luciferase activity (70.7 and $47.9 \%$, respectively) when compared to the WT vector $(p<0.01$; Fig. $3 \mathrm{a})$, suggesting that a substitution in $\mathrm{Sp} 1$ caused the reduced transcriptional activity of pre-S1 mRNA.

To further investigate whether a substitution in the Sp1 site could influence the expression of L protein, we analyzed the changes in pre-S1 mRNA and L protein expression using pre-S1 expression vectors. First, we analyzed pre-S1 mRNA and L protein expression by using an expression vector that included the transcription-regulating regions to the end of the $\mathrm{S}$ region. Pre-S1 mRNA expression was significantly decreased in the cells transfected with the $\mathrm{m} 5$ or $\mathrm{m} 9$ vector when compared to those transfected with the WT vector $(79.4 \%, p<0.01$ and $74.1 \%, p<0.01$, respectively; Fig. $3 \mathrm{~b})$. The expression of $\mathrm{L}$ protein was significantly decreased in the cells transfected with the $\mathrm{m} 5$ or $\mathrm{m} 9$ vector when compared to those transfected with the WT vector $(p<0.01$, respectively;

Table 3 G2765A substitution ratios determined by TA cloning or next-generation sequencing

\begin{tabular}{|c|c|c|c|}
\hline TA cloning ${ }^{a}$ & Substitution percentage & $\mathrm{NGS}^{\mathrm{a}}$ & Substitution percentage \\
\hline $1 / 15$ & $6.67 \%$ & $44 / 6155$ & $0.71 \%$ \\
\hline $0 / 15$ & $0.00 \%$ & $1 / 3955$ & $0.03 \%$ \\
\hline $0 / 15$ & $0.00 \%$ & $10 / 5327$ & $0.19 \%$ \\
\hline $9 / 15$ & $60.00 \%$ & $4866 / 8081$ & $60.22 \%$ \\
\hline $0 / 16$ & $0.00 \%$ & $7 / 10409$ & $0.07 \%$ \\
\hline $0 / 15$ & $0.00 \%$ & $2 / 7304$ & $0.03 \%$ \\
\hline $0 / 15$ & $0.00 \%$ & $9 / 6662$ & $0.14 \%$ \\
\hline $1 / 25$ & $4.00 \%$ & $22 / 6258$ & $0.35 \%$ \\
\hline $1 / 16$ & $6.25 \%$ & $49 / 1643$ & $2.98 \%$ \\
\hline $0 / 15$ & $0.00 \%$ & $1 / 2740$ & $0.04 \%$ \\
\hline
\end{tabular}

These samples were selected from high HBV viral load (8.2-7.2 log IU/ml) patients

${ }^{a}$ Number of samples with the G2765A substitution/total number of samples

Abbreviation: NGS next-generation sequencing 

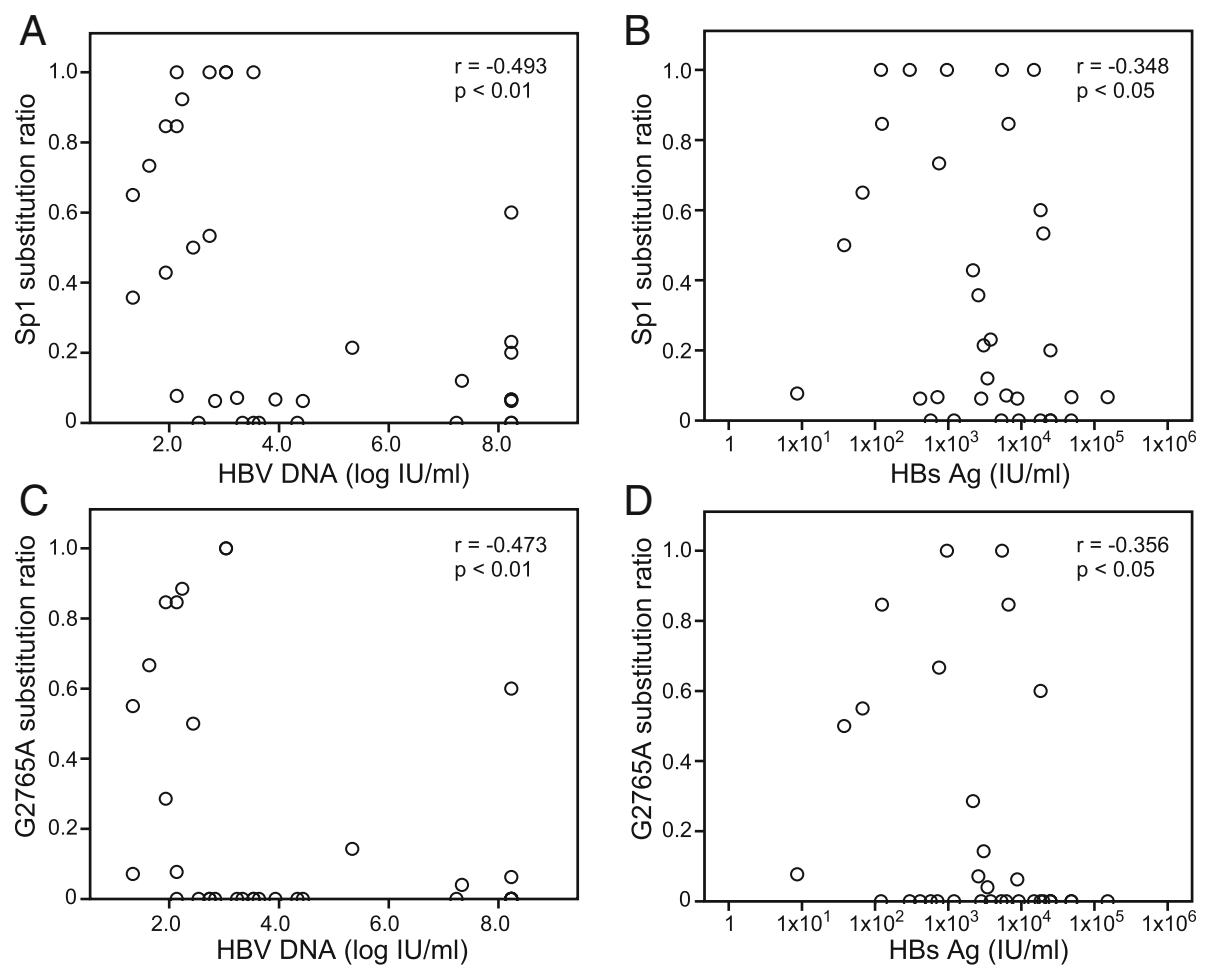

Fig. 2 Correlation between the substitution ratio and HBV-related parameters. a The Sp1 substitution ratio and the HBV DNA viral load showed a negative correlation, and (b) the Sp1 substitution ratio and the HBsAg level showed a weak negative correlation. c The G2765A substitution ratio and the HBV DNA viral load showed a negative correlation, and (d) the G2765A substitution ratio and the HBsAg level showed a weak negative correlation

Fig. 3c-e). These results clearly indicated that a substitution in the $\mathrm{Sp} 1$ site reduced the transcription of the L protein.

\section{The Sp1 G2765A substitution reduced the level of pre-S1 antigen}

To further investigate the effect of the G2765A substitution on HBV production, we constructed a 1.3-fold HBV genome vector that enabled the production of HBV particles when transfected into HepG2 cells. Transfection of

Table 4 Occurrence of substitutions at different sites among patients with a high (>5.0 log IU/ml) or low ( $\leq 5.0 \mathrm{log} \mathrm{IU} / \mathrm{ml})$ HBV DNA viral load

\begin{tabular}{llll}
\hline & High $(n=11)$ & Low $(n=24)$ & $\mathrm{p}$ \\
\hline HNF1 & 0 & 0 & $>0.999$ \\
HNF3 & 0 & 0 & $>0.999$ \\
Sp1 & 1 & 12 & 0.027 \\
$\quad$ G2765A & 1 & 8 & 0.219 \\
T2768G/A & 0 & 2 & $>0.999$ \\
C2771T & 0 & 2 & $>0.999$ \\
TATA & 0 & 1 & $>0.999$ \\
T2780C & 0 & 1 & $>0.999$ \\
\hline
\end{tabular}

the m5 (G2765A) or WT vector into HepG2 cells resulted in no change in virus production $(5.6 \log \mathrm{IU} / \mathrm{ml}$, $5.7 \log \mathrm{IU} / \mathrm{ml}$, respectively). However, the expression of the $\mathrm{L}$ protein was significantly decreased in both the cell lysate (Fig. 3f-h) and supernatant (Fig. 3i-k) of HepG2 cells transfected with the $\mathrm{m} 5$ vector when compared to those transfected with the WT vector $(p<0.01$, respectively).

\section{Discussion}

In the present study, we found that there were several mutation sites in the pre-S1 promoter region of HBV, among which $\mathrm{Sp} 1$ was the most common mutation site. In addition, patients who had a mutation in the pre-S1 promoter region showed less severe disease (for example, lower aminotransferase levels, higher rate of HBeAb positivity, and lower HBV viral load) than those who did not, and the Sp1 substitution ratio was negatively correlated with the HBV amount. Moreover, our in vitro study using cultured cells showed that the expression of $\mathrm{L}$ protein was significantly decreased by a single nucleotide change from $\mathrm{G}$ to $\mathrm{A}$ at the 2765th base in the Sp1 site.

It has been reported that the risk of chronic hepatitis $B$ progression is associated with several HBV viral 
Table 5 Characteristics of patients in the low HBV viral load group according to Sp1 and the G2765A substitution

\begin{tabular}{|c|c|c|c|c|c|}
\hline & \multirow[b]{2}{*}{ Wild type $(n=12)$} & \multicolumn{2}{|l|}{ Sp1 } & \multicolumn{2}{|l|}{ G2765A } \\
\hline & & Substitution $(n=12)$ & $p$ & Substitution $(n=8)$ & $\mathrm{p}$ \\
\hline Male (n (\%)) & $4(33.3 \%)$ & $9(75.0 \%)$ & 0.1 & $6(75.0 \%)$ & 0.170 \\
\hline Age (years) & $53.9(35-81)$ & $58.2(32-74)$ & 0.522 & $63.4(46-74)$ & 0.150 \\
\hline HBV DNA (log IU/ml) & $3.9(1.3-4.4)$ & $3.2(1.3-3.5)$ & 0.061 & $2.2(1.3-3.0)$ & 0.040 \\
\hline HBsAg (IU/ml) & $4129(8.61-18,268)$ & $4483(37.7-19,986)$ & 0.525 & $2007(37.7-6670)$ & 0.340 \\
\hline HBeAg positive (n (\%)) & $0(0 \%)$ & $0(0 \%)$ & $>0.999$ & $0(0 \%)$ & $>0.999$ \\
\hline HBeAb positive (n (\%)) & $12(100 \%)$ & $12(100 \%)$ & $>0.999$ & $8(100 \%)$ & $>0.999$ \\
\hline AST $(U / L)$ & $26.8(19-50)$ & $22.0(11-40)$ & 0.074 & $19.0(11-24)$ & 0.011 \\
\hline $\operatorname{ALT}(U / L)$ & $31.9(14-90)$ & $20.2(11-40)$ & 0.235 & $18.8(10-27)$ & 0.162 \\
\hline Platelet count $\left(10^{4} / \mu \mathrm{l}\right)$ & $17.7(13.9-22.5)$ & $17.4(10.9-22.6)$ & 0.921 & $17.5(10.9-22.6)$ & 0.955 \\
\hline
\end{tabular}

Abbreviations: $H B V$ hepatitis B virus, $H B s A g$ hepatitis B surface antigen, $H B e A g$ hepatitis $B$ e antigen, $H B e A b$ hepatitis $B$ e antibody, $A S T$ aspartate transaminase, $A L T$ alanine transaminase

factors, including the viral load, HBsAg level, and HBV genotype. Patients with a high viral load or high $\mathrm{HBsAg}$ level are reported to have a higher risk of HCC, especially in patients with genotype $\mathrm{C}$ when compared to those with genotype $B[8,27]$. In contrast, patients with a low HBV DNA load and low HBsAg level have a lower risk of disease progression, and these are associated with HBsAg seroclearance $[28,29]$. Furthermore, HBV mutations affect the prognosis of HBV patients. The A1762T and G1764A mutations in the basic core promoter region are associated with an increased risk of HCC in genotype $C$ patients [8]. Based on the above, we hypothesized that a mutation in the pre-S1 promoter region might affect the prognosis of HBV infection.

Our data from the clinical samples showed that the G2765A substitution was associated with a lower HBV DNA load. We think the most probable explanation for this is that the substitution reduces the production of $\mathrm{L}$ protein, which plays a crucial role in the virion secretion [15]. Our transfection experiments using cultured cells showed that a mutation in the Sp1 site significantly reduced the transcription of $\mathrm{L}$ protein mRNA and L protein production, lowering the $\mathrm{L} / \mathrm{S}$ protein ratio. These results suggest the possibility that a mutation in Sp1 promoter region reduces the expression of $\mathrm{L}$ protein, consequently inhibiting virion secretion, thus leading to a lower viral load and silent disease in the long run.

Nevertheless, it remains unclear how HBV with a mutation in the pre-S1 promoter region could become dominant even though it is likely less infectious to hepatocytes due it the lower viral load. We speculated that the reason might be related to the immune response. The envelope proteins of HBV are immunogenic, and L protein contains both $\mathrm{B}$ - and $\mathrm{T}$-cell epitopes and plays an important role in the immune responses [14]. HBV is constantly exposed to host immune pressure, and HBV with mutations that allow it to escape from that pressure are able to survive. Reduced levels of $\mathrm{L}$ protein caused by the G2765A substitution may enable HBV to escape immune pressure, making it possible to persist in the hepatocytes of patients. In fact, the aminotransferase levels of patients infected with the G2765A mutant HBV tend to be low, indicating that the immune responses of those patients are weak.

Our findings may also shed light on how a decrease in L protein level allows HBV to remain alive in hepatocytes. Much evidence has been reported on the role of $\mathrm{L}$ protein in several stages of HBV production. Garcia et al. proposed that either a sufficiently high or low L/S protein ratio inhibited virion secretion [15], and this was corroborated by our finding that patients infected with the G2765A mutant HBV showed a lower HBV DNA load. In addition, Lentz et al. argued that ablation of the expression of envelope proteins causes an increase in cccDNA, and $\mathrm{L}$ protein regulates the amplification of cccDNA [16]. Our results suggest the possibility that the G2765A substitution reduced L protein levels, leading to an increase in the number of cccDNA, which is difficult to eliminate from hepatocytes. It's as if HBV has "gone underground like the Resistance" for survival. However, the relationship between the cccDNA level and the prognosis of $\mathrm{HBV}$-infected patients remains poorly understood. In fact, G2765A mutant HBV-infected patients showed less severe disease. Therefore, the G2765A substitution is considered to serve as a marker of good prognosis.

The present study has several limitations. First, it was performed with a relatively small number of patients. The reason for this was the very strict inclusion criteria used for the study. We focused only on genotype $\mathrm{C}$-infected patients, because it is the genotype that is mainly found in East Asia, and more than $80 \%$ of chronic HBV-infected patients have genotype $\mathrm{C}$ HBV in Japan [3]. In addition, genotype C HBV infection is more burdensome than HBV infection with the other genotypes, because it is associated with a higher risk of 


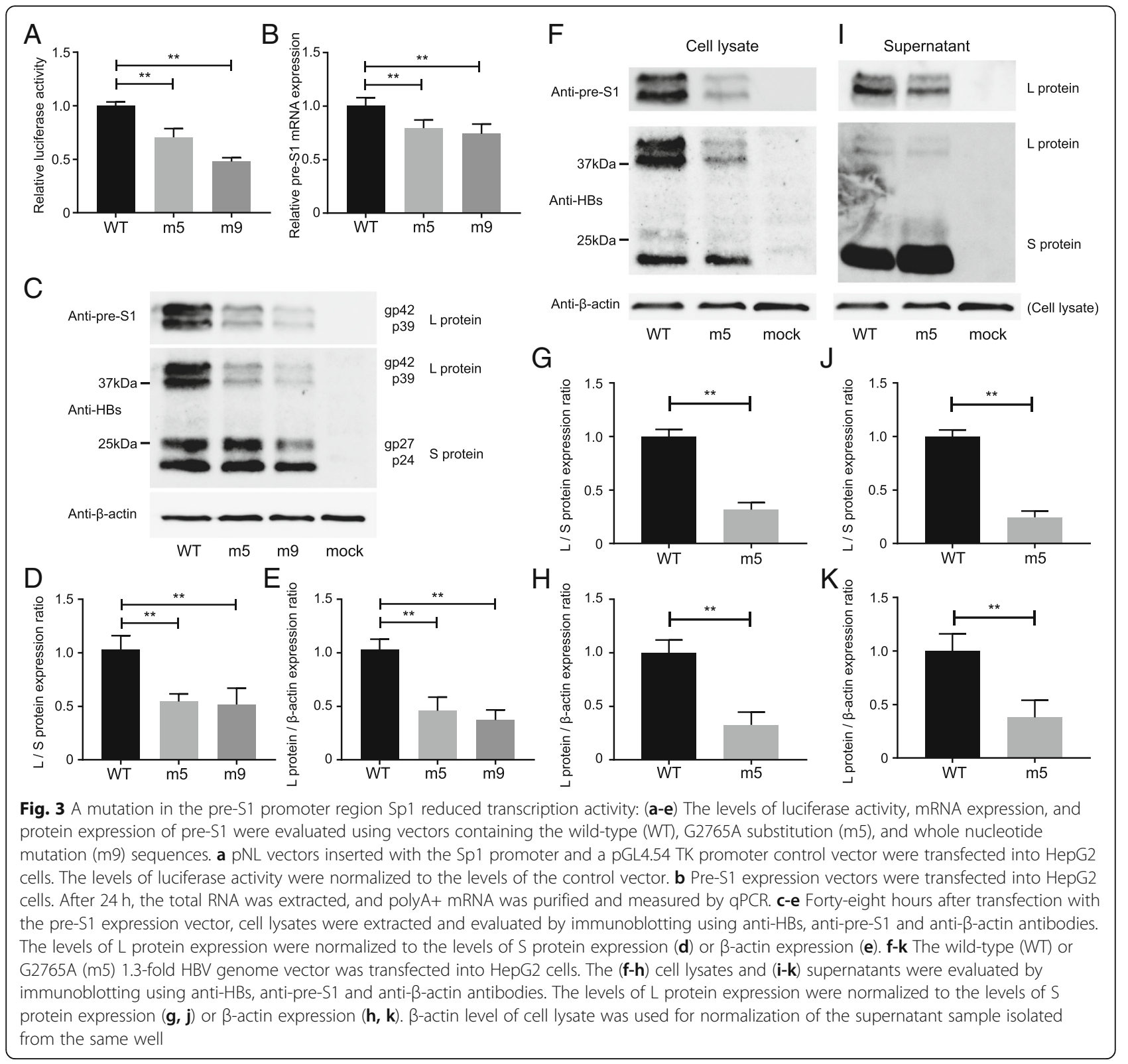

cirrhosis and $\mathrm{HCC}$, and tends to be resistant to antiviral therapy. In clinical settings, HBV genotypes are usually determined serologically using commercial enzyme immunoassay (EIA) kits that detect the pre-S2 epitope. However, different HBV genotypes can simultaneously infect the same host, and in that situation, the results of EIA may be scrambled; as such, in this study, we confirmed the genotype by both EIA and viral sequencing, and we excluded the subjects for whom the genotyping results were inconsistent. Furthermore, we also excluded the patients who had chronic co-infection with another virus, other liver diseases, or a history of using any kind of medications that could influence the viral and immune status (for example, nucleotide analogues, interferon, immunosuppressants, steroids, anticancer agents, biologic agents, etc.). These strict inclusion/ exclusion criteria resulted in a small sample size; however, we believe it also made our data very solid and reliable. Another limitation of the study was our failure to clarify whether HBV with the G2765A substitution is actually less infectious to hepatocytes, and we could not directly show whether the mutation is associated with a decrease in the $\mathrm{L} / \mathrm{S}$ protein ratio in patient sera due to technical reasons. In addition, we could not perform a long-term survey to prove whether the mutation occurred prior to the reduction in HBV DNA. Further studies are needed for addressing these issues. 


\section{Conclusion}

In conclusion, despite several limitations, our present study demonstrated for the first time the possibility that mutations in the pre-S1 promoter region, especially the G2765A substitution in the Sp1 region, reduce the expression of $\mathrm{L}$ protein and regulate biological character of virus, leading to a low viral load and less severe disease in chronic HBV infection.

\section{Abbreviations}

AST: Aspartate transaminase; cccDNA: Covalently closed circular DNA; ElA: Enzyme immunoassay; HBeAg: Hepatitis B e antigen; HBsAg: Hepatitis B surface antigen; HBV: Hepatitis B virus; NA: Nucleos(t)ide analogue; NGS: Next-generation sequencing; NTCP: Sodium taurocholate cotransporting polypeptide; qPCR: Quantitative real-time polymerase chain reaction

\section{Acknowledgments}

We thank Mie University Center for Molecular Biology and Genetics for NGS sample preparation and analysis. We thank Ms. Mina Tenpaku for her technical assistance.

\section{Funding}

Not applicable.

\section{Availability of data and materials}

The datasets generated and analyzed during the current study are available in the DNA Data Bank of Japan under accession number LC360507 and DRA006472.

\section{Authors' contributions}

Conceived and designed the experiments: KS. Performed the experiments: SO MT KS. Analyzed the data: MT MI1. Wrote the paper: MT KS. Edited the paper: KS MT, MU, MI2, YT. MI1 stands for Makoto Ikejiri, MI2 stands for Masaaki Ito. All authors read and approved the final manuscript.

\section{Ethics approval and consent to participate}

This study was approved by the Institutional Review Board of Mie University Hospital. The study protocol conformed to the ethical guidelines of the 1975 Declaration of Helsinki, as reflected in the a priori approval by the institution's human research committee.

\section{Consent for publication}

Written informed consent was obtained from each patient included in the study.

\section{Competing interests}

Masaaki Ito received honoraria for lecture fees from Daiichi Sankyo Co., Ltd. Bayer Yakuhin, Ltd. and Takeda Pharmaceutical Co., Ltd., and departmental scholarship funds from Bristol-Myers Squibb, MSD K.K., Shionogi \& Co., Ltd., Otsuka Pharmaceutical Co., Ltd., Takeda Pharmaceutical Co., Ltd. and Daiichi Sankyo Co., Ltd.

Yoshiyuki Takei received honoraria for lecture fees from Otsuka Pharmaceutical Co., Ltd. and departmental scholarship funds from Astellas Pharma Inc., Eisai Co., Ltd., Otsuka Pharmaceutical Co., Ltd., Daiichi Sankyo Co., Ltd., Takeda Pharmaceutical Co., Ltd., Suntory Global Innovation Center Ltd. and Kyokuto Pharmaceutical Industrial Co. Ltd.

The companies associated with this funding were not involved in the preparation of the manuscript or the decision to publish the present study. The other authors declare no conflicts of interest in association with the present study.

\section{Publisher's Note}

Springer Nature remains neutral with regard to jurisdictional claims in published maps and institutional affiliations.

\section{Author details}

'Department of Gastroenterology and Hepatology, Mie University Graduate School of Medicine, 2-174 Edobashi, Tsu, Mie 514-8507, Japan. ²Department of Central Laboratory, Mie University Hospital, Tsu, Japan. ${ }^{3}$ Department of Hepatobiliary Pancreatic and Transplant Surgery, Mie University Graduate School of Medicine, Tsu, Japan. ${ }^{4}$ Department of Cardiology and Nephrology, Mie University Graduate School of Medicine, Tsu, Japan.

Received: 24 July 2018 Accepted: 23 April 2019

Published online: 02 May 2019

\section{References}

1. World Health Organization. Global hepatitis report 2017. World Health Organization. 2017. http://www.who.int/iris/handle/10665/255016.

2. Tanaka J, Akita T, Ohisa M, Sakamune K, Ko K, Uchida S, Satake M. Trends in the total numbers of HBV and HCV carriers in Japan from 2000 to 2011. J Viral Hepat. 2018;25:363-72.

3. Matsuura K, Tanaka Y, Hige S, Yamada G, Murawaki Y, Komatsu M, Kuramitsu T, Kawata S, Tanaka E, Izumi N, et al. Distribution of hepatitis B virus genotypes among patients with chronic infection in Japan shifting toward an increase of genotype a. J Clin Microbiol. 2009;47:1476-83.

4. Girones R, Miller RH. Mutation rate of the hepadnavirus genome. Virology. 1989;170:595-7.

5. Jazayeri SM, Alavian SM, Carman WF. Hepatitis B virus: origin and evolution. J Viral Hepat. 2010;17:229-35

6. Orito E, Mizokami M, Ina Y, Moriyama EN, Kameshima N, Yamamoto M, Gojobori T. Host-independent evolution and a genetic classification of the hepadnavirus family based on nucleotide sequences. Proc Natl Acad Sci U S A. $1989 ; 86: 7059-62$.

7. Buckwold VE, Xu Z, Chen M, Yen TS, Ou JH. Effects of a naturally occurring mutation in the hepatitis B virus basal core promoter on precore gene expression and viral replication. J Virol. 1996;70:5845-51.

8. $\quad$ Yang HI, Yeh SH, Chen PJ, Iloeje UH, Jen CL, Su J, Wang LY, Lu SN, You SL, Chen DS, et al. Associations between hepatitis B virus genotype and mutants and the risk of hepatocellular carcinoma. J Natl Cancer Inst. 2008; 100:1134-43.

9. Allen MI, Deslauriers M, Andrews CW, Tipples GA, Walters KA, Tyrrell DL, Brown N, Condreay LD. Identification and characterization of mutations in hepatitis B virus resistant to lamivudine. Lamivudine clinical investigation group. Hepatology. 1998;27:1670-7.

10. Carman WF, Zanetti AR, Karayiannis P, Waters J, Manzillo G, Tanzi E, Zuckerman AJ, Thomas HC. Vaccine-induced escape mutant of hepatitis B virus. Lancet. 1990;336:325-9.

11. Pollicino T, Amaddeo G, Restuccia A, Raffa G, Alibrandi A, Cutroneo G, Favaloro A, Maimone S, Squadrito G, Raimondo G. Impact of hepatitis B virus (HBV) preS/S genomic variability on HBV surface antigen and HBV DNA serum levels. Hepatology. 2012;56:434-43.

12. Yan $H$, Zhong G, Xu G, He W, Jing Z, Gao Z, Huang Y, Qi Y, Peng B, Wang H, et al. Sodium taurocholate cotransporting polypeptide is a functional receptor for human hepatitis B and D virus. eLife. 2012;1:e00049.

13. Poisson F, Severac A, Hourioux C, Goudeau A, Roingeard P. Both pre-S1 and $S$ domains of hepatitis $B$ virus envelope proteins interact with the Core particle. Virology. 1997;228:115-20.

14. Chen BF, Liu CJ, Jow GM, Chen PJ, Kao JH, Chen DS. High prevalence and mapping of pre-S deletion in hepatitis $B$ virus carriers with progressive liver diseases. Gastroenterology. 2006;130:1153-68.

15. Garcia T, Li J, Sureau C, Ito K, Qin Y, Wands J, Tong S. Drastic reduction in the production of subviral particles does not impair hepatitis B virus virion secretion. J Virol. 2009;83:11152-65.

16. Lentz TB, Loeb DD. Roles of the envelope proteins in the amplification of covalently closed circular DNA and completion of synthesis of the plusstrand DNA in hepatitis B virus. J Virol. 2011;85:11916-27.

17. Raney AK, Easton AJ, Milich DR, McLachlan A. Promoter-specific transactivation of hepatitis B virus transcription by a glutamine- and prolinerich domain of hepatocyte nuclear factor 1. J Virol. 1991;65:5774-81.

18. Raney AK, Zhang P, McLachlan A. Regulation of transcription from the hepatitis B virus large surface antigen promoter by hepatocyte nuclear factor 3. J Virol. 1995;69:3265-72.

19. Raney AK, McLachlan A. Characterization of the hepatitis B virus large surface antigen promoter Sp1 binding site. Virology. 1995;208:399-404. 
20. Usuda S, Okamoto H, Iwanari H, Baba K, Tsuda F, Miyakawa Y, Mayumi M. Serological detection of hepatitis B virus genotypes by ELISA with monoclonal antibodies to type-specific epitopes in the preS2-region product. J Virol Methods. 1999:80:97-112.

21. Bolger AM, Lohse M, Usadel B. Trimmomatic: a flexible trimmer for Illumina sequence data. Bioinformatics. 2014;30:2114-20.

22. Vaz C, Ahmad HM, Sharma P, Gupta R, Kumar L, Kulshreshtha R, Bhattacharya A. Analysis of microRNA transcriptome by deep sequencing of small RNA libraries of peripheral blood. BMC Genomics. 2010;11:288.

23. Robinson JT, Thorvaldsdottir H, Winckler W, Guttman M, Lander ES, Getz G, Mesirov JP. Integrative genomics viewer. Nat Biotech. 2011;29:24-6.

24. Gunther S, Li BC, Miska S, Kruger DH, Meisel H, Will H. A novel method for efficient amplification of whole hepatitis B virus genomes permits rapid functional analysis and reveals deletion mutants in immunosuppressed patients. J Virol. 1995:69:5437-44.

25. Guidotti LG, Matzke B, Schaller H, Chisari FV. High-level hepatitis B virus replication in transgenic mice. J Virol. 1995;69:6158-69.

26. Hemsley A, Arnheim N, Toney MD, Cortopassi G, Galas DJ. A simple method for site-directed mutagenesis using the polymerase chain reaction. Nucleic Acids Res. 1989;17:6545-51.

27. Chen CJ, Yang HI, Su J, Jen CL, You SL, Lu SN, Huang GT, lloeje UH. Risk of hepatocellular carcinoma across a biological gradient of serum hepatitis B virus DNA level. Jama. 2006;295:65-73.

28. Liu J, Yang HI, Lee $M H$, Jen CL, Batrla-Utermann R, Lu SN, Wang LY, You SL, Chen CJ. Serum levels of hepatitis B surface antigen and DNA can predict inactive carriers with low risk of disease progression. Hepatology. 2016;64:381-9.

29. Liu J, Tseng TC, Yang HI, Lee MH, Batrla-Utermann R, Jen CL, Lu SN, Wang $L Y$, You SL, Chen PJ, et al. Predicting hepatitis B virus (HBV) surface antigen Seroclearance in HBV e antigen-negative patients with chronic hepatitis B: external validation of a scoring system. J Infect Dis. 2015;211:1566-73.

Ready to submit your research? Choose BMC and benefit from:

- fast, convenient online submission

- thorough peer review by experienced researchers in your field

- rapid publication on acceptance

- support for research data, including large and complex data types

- gold Open Access which fosters wider collaboration and increased citations

- maximum visibility for your research: over $100 \mathrm{M}$ website views per year

At $\mathrm{BMC}$, research is always in progress.

Learn more biomedcentral.com/submissions 